\title{
Challenges and opportunities for ovarian cancer management in the epidemic of Covid-19: lessons learned from Wuhan, China
}

Zhilan Chen ${ }^{1+} \mathbb{D}$, Chun Zhang ${ }^{1+}$, Jiu Yin ${ }^{1}$, Xin Xin ${ }^{1}$, Hemei Li ${ }^{1}$, Yapei Wang ${ }^{1}$, Benjamin K. Tsang ${ }^{2}$ and Qinghua Zhang ${ }^{1 *}$

\begin{abstract}
China and the rest of the world are experiencing an outbreak of the 2019 novel coronavirus disease (COVID-19). Patients with cancer are more susceptible to viral infection and are more likely to develop severe complications, as compared to healthy individuals. The growing spread of COVID-19 presents challenges for the clinical care of patients with gynecological malignancies. Ovarian debulking surgery combined with the frequent need for chemotherapy is most likely why ovarian cancer was rated as the gynecologic cancer most affected by COVID-19. Therefore, ovarian cancer presents a particular challenging task. Concerning the ovarian cancer studies with confirmed COVID-19 reported from large-scale general hospitals in Wuhan, we hold that the treatment plan was adjusted appropriately and an individualized remedy was implemented. The recommendations discussed here were developed mainly based on the experience from Wuhan. We advise that the management strategy for ovarian cancer patients should be adjusted in the light of the local epidemic situation and formulated according to the pathological type, tumor stage and the current treatment phase. Online medical service is an effective and convenient communication platform during the pandemic.
\end{abstract}

Keywords: Covid-19, Ovarian cancer, Pandemic, Management

\section{Introduction}

Severe acute respiratory syndrome coronavirus 2 (SARSCoV-2), a novel coronavirus, emerged in the city of Wuhan, Hubei, China in early December, 2019 [48]. Since its first identification, coronavirus disease 2019 (COVID-19) has spread to over 200 countries with 103, 402,619 cases and a total of 2,232,194 deaths worldwide (as of Februrary 0152,2021 ), according to the World

\footnotetext{
* Correspondence: zhangqh66@qq.com

'Zhilan Chen and Chun Zhang contributed equally to this work.

'Department of Obstetrics and Gynecology, The Central Hospital of Wuhan

Tongji Medical College, Huazhong University of Science and Technology, No. 26 Shengli Street, Jiangan District, Wuhan 430014, China

Full list of author information is available at the end of the article
}

Health Organization reports (https://www.who.int/ emergencies/diseases/novelcoronavirus-2019/situationreports). Since then, local and national governments have taken unprecedented measures in response to the COVID-19 outbreak. Wuhan realized zero growth of suspected or confirmed new cases on March 18, 2000. Subsequently, Wuhan was classified as a "low-risk" area on April 18. From the "storm center" of the epidemic to the "safest city in China" in the eyes of many academicians and experts, Wuhan has realized the fundamental reversal of the situation by implementing the national treatment strategies of "all those in need are tested, quarantined, hospitalized or treated". Table 1 illustrates

C C The Author(s). 2021 Open Access This article is licensed under a Creative Commons Attribution 4.0 International License, which permits use, sharing, adaptation, distribution and reproduction in any medium or format, as long as you give appropriate credit to the original author(s) and the source, provide a link to the Creative Commons licence, and indicate if changes were made. The images or other third party material in this article are included in the article's Creative Commons licence, unless indicated otherwise in a credit line to the material. If material is not included in the article's Creative Commons licence and your intended use is not permitted by statutory regulation or exceeds the permitted use, you will need to obtain permission directly from the copyright holder. To view a copy of this licence, visit http://creativecommons.org/licenses/by/4.0/ The Creative Commons Public Domain Dedication waiver (http://creativecommons.org/publicdomain/zero/1.0/) applies to the data made available in this article, unless otherwise stated in a credit line to the data. 
Table 1 Chronology of major significant events during the pandemic in Wuhan

\begin{tabular}{|c|c|}
\hline Date (2020) & Major events \\
\hline $\begin{array}{l}\text { January } 23 \text { rd } \\
\text { (10:00 h) }\end{array}$ & $\begin{array}{l}\text { City bus, subway, ferry, long-distance passenger trans- } \\
\text { port, airport and railway station in Wuhan were tem- } \\
\text { porarily closed }\end{array}$ \\
\hline February 5th & $\begin{array}{l}\text { Mobile cabin hospitals began to receive COVID-19 pa- } \\
\text { tients with mild symptoms. }\end{array}$ \\
\hline February 4-8 & $\begin{array}{l}\text { Huoshenshan hospital and Leishenshan hospital were } \\
\text { put into use to receive severe patients }\end{array}$ \\
\hline February 18th & $\begin{array}{l}\text { Cumulative number of confirmed cases reached the } \\
\text { peak figure of } 38,020\end{array}$ \\
\hline February 29th & $\begin{array}{l}\text { The quarantine places, mobile cabin hospitals, and } \\
\text { designated hospitals in Wuhan all had available extra } \\
\text { beds for the first time }\end{array}$ \\
\hline March 1st & $\begin{array}{l}\text { The first closed mobile cabin hospital appeared in } \\
\text { Wuhan }\end{array}$ \\
\hline March 10th & $\begin{array}{l}\text { All sixteen mobile cabin hospitals in Wuhan were } \\
\text { closed. }\end{array}$ \\
\hline March 13th & $\begin{array}{l}\text { Zero increase of suspected case in Wuhan for the first } \\
\text { time }\end{array}$ \\
\hline March 18th & $\begin{array}{l}\text { Zero increase of suspected case or confirmed case in } \\
\text { Wuhan for the first time }\end{array}$ \\
\hline March 25th & Wuhan was classified as "medium risk" area \\
\hline April 6th & Zero increase of motality case \\
\hline April 8th $(0: 00 \mathrm{~h})$ & $\begin{array}{l}\text { Wuhan city lifted the control measures. Wuhan had } \\
\text { been closed for } 76 \text { days since 10:00,January } 23 \text {. }\end{array}$ \\
\hline April 18th & Wuhan was classified as "low risk" area as a whole \\
\hline April 23rd & Severe COVID-19 cases in Wuhan were eliminated. \\
\hline April 24th & $\begin{array}{l}\text { The in-hospital COVID-19 patients in Wuhan were } \\
\text { cleared. }\end{array}$ \\
\hline
\end{tabular}

the chronology of major events of historical significance in relation to the pandemic.

Patients with cancer are more susceptible to viral infection and might be at increased risk for COVID-19. They have a poorer prognosis than healthy individuals because of their systematic immunosuppressive status caused by the tumor burden and anticancer treatments, such as surgery or chemotherapy [35]. The report indicated that the fatality rate for COVID-19 patients with cancer was $7.6 \%$ vs. fatality rate of $3.8 \%$ in the entire COVID-19 population [39]. Data from different countries are displayed in Table $2[5,6,8,9,15,17,18,20$, 23-25, 27, 30-33, 36, 37, 40, 42, 44, 45, 47, 48] Chen et al. found that $2019 \mathrm{nCoV}$ is more likely to infect older adult males with chronic comorbidities as a result of the weaker immune functions [7]. Liang et al. concluded that among patients with cancer, age is the only risk factor for the severity of the illness [22]. Dai et al. reported that cancer types, stage and treatments may contribute to the severity of the diseases among patients with cancer. However, when patients with cancer only had early stage malignancy without metastasis, the authors failed to observe any difference between the cancer and noncancer population in terms of COVID-19 related death rate or severity [12]. Liang et al. showed that, compared to patients without cancer, cancer patients were older, more likely to have a history of smoking, had more polypnea, and more severe baseline computed tomography (CT) manifestation. They however had no significant differences in sex, baseline symptoms, other comorbidities, or baseline severity of x-ray [22].

During the COVID-19 pandemic, the utmost risk for patients with cancer is limited access to required health care and inability to receive necessary medical services in a timely fashion, especially in high-risk epidemic areas like Wuhan, where there is a high demand on medical faculty and health care facilities [35]. In the survey, responders reported a $60 \%$ decline in clinical volume which implies that there were gynecologic cancer patients who were unable to receive prompt medical attention until COVID-19 fades. A majority of responders $(52.8 \%)$ believed that ovarian cancer will be the gynecologic cancer most affected by COVID-19. This was followed by uterine cancer (30.0\%), and cervical cancer (14.8\%) [26]. Ovarian debulking surgery was ranked as the treatment of most concern during the pandemic. This combined with the frequent need for chemotherapy could likely explain why ovarian cancer was rated as the most impacted gynecologic cancer by COVID-19, and thus a particular challenge.

On January 23, 2020, Wuhan began to be locked down, and most departments of gynecology were closed and surgeries and chemotherapy for ovarian cancer were suspended. By the middle of February, some patients have not been treated with chemotherapy for more than 6 weeks. The long interval led to tumor progression. In order to facilitate timely treatment, Wuhan opened 9 designated large-scale general hospitals for covid-19 free cases on February 16, and that figure rose to 40 on March 18th. Divisions of gynecology joined efforts with infection control divisions to transform the ward, strengthen the protection, and provided patients with necessary education about disease prevention and control. In China, the governmental guideline demands that patients with confirmed COVID-19 positive be transferred to hospitals designated by the local governments for COVID-19 treatments.

To date, the pandemic situation in China has improved significantly, with both the number of new cases and fatality markedly reduced. The spread of COVID-19 in Wuhan was effectively controlled and patient care, including cancer treatment, gradually returned to normal. To ensure effective treatment of patients with cancer while avoiding cross infection of COVID-19, greater attention was paid by clinicians to the complex condition of different COVID-19 epidemic phases. Therefore, it is 
Table 2 Mortality rate for COVID-19 patients with cancer

\begin{tabular}{|c|c|c|c|c|c|}
\hline References & Country & Study Design & Deaths & Total & $\%$ \\
\hline Wang J et al [36] & China & Multicenter, retrospective cohort & 50 & 283 & 17.7 \\
\hline Zhang J-X et al [47] & China & Single-center retrospective cohort & 1 & 14 & 7.1 \\
\hline Zhang $\mathrm{H}-\mathrm{Y}$ et al [44] & China & Multicenter, retrospective cohort & 18 & 67 & 26.9 \\
\hline Zhang L et al [48] & China & Multicenter, retrospective cohort & 8 & 28 & 28.6 \\
\hline Yang K-Y et al [40] & China & Multicenter, retrospective cohort & 40 & 205 & 19.5 \\
\hline Zhang H-Y et al [45] & China & Multicenter, retrospective cohort & 14 & 37 & 37.8 \\
\hline Meng Y-F et al [24] & China & Single-center retrospective cohort & 32 & 109 & 29.4 \\
\hline Chen T-L et al [9] & China & Single-center retrospective cohort & 1 & 7 & 14.3 \\
\hline Chen T et al [8] & China & Single-center retrospective cohort & 5 & 7 & 71.4 \\
\hline Guan W-J et al [15] & China & Multicenter, retrospective cohort & 3 & 18 & 16.7 \\
\hline Wang L et al [37] & China & Single-center retrospective cohort & 3 & 15 & 20.0 \\
\hline Basse C et al [5] & France & Single-center, prospective cohort & 26 & 141 & 18.4 \\
\hline Nikpouraghdam M et al [27] & Iran & Single-center retrospective cohort & 1 & 17 & 5.9 \\
\hline Trapani D et al [33] & Italy & Single-center retrospective cohort & 150 & 909 & 16.5 \\
\hline Rossi PG et al [31] & Italy & Multi-center retrospective cohort & 44 & 301 & 14.6 \\
\hline Benelli G et al [6] & Italy & Single-center retrospective cohort & 9 & 33 & 27.3 \\
\hline Yarza R et al [42] & Spain & Multi-center retrospective cohort & 16 & 63 & 25.4 \\
\hline Russell B et al [32] & UK & Single-center retrospective cohort & 34 & 156 & 21.8 \\
\hline Joharatnam-Hogan $\mathrm{N}$ et al [17] & UK & Multicenter, retrospective cohort & 6 & 26 & 23.1 \\
\hline Lee L-Y et al [20] & UK & Multicenter, prospective cohort & 226 & 800 & 28.3 \\
\hline Miyashita $\mathrm{H}$ et al [25] & US & Multicenter, retrospective cohort & 37 & 334 & 11.1 \\
\hline Mehta V et al [23] & US & Single-center retrospective cohort & 61 & 218 & 28.0 \\
\hline Kuderer NM et al [18] & US & Multicenter, retrospective cohort & 121 & 928 & 13.0 \\
\hline Robilotti EV et al [30] & US & Single-center retrospective cohort & 39 & 423 & 9.2 \\
\hline
\end{tabular}

of significance to summarize the relevant experience in the prevention, control of COVID-19 infection and treatment of cancer patients in Wuhan during the epidemic.

\section{Managements were adjusted in light of the local epidemic situation}

During the epidemic, it is important that cancer treatment be adjusted according to the local epidemic status so as to reduce the risk of tumor progression as well as COVID 19 infection. In regard to patients and hospitals in areas with serious or high-risk epidemic situation, such as Wuhan before COVID-19 was under control, strict precautions against the infection and spread of the epidemic was the first priority, and then followed by cancer treatment. Doctors and patients used online medical service to assess whether chemotherapy or surgery should be postponed. Medical personnel paid greater attention to patients after radiotherapy and chemotherapy and discriminated side effects associated with tumor treatment from possible symptoms of covid-19 infection, including fever, vomiting and diarrhea.
In the early stage of the epidemic, patients and health care providers were at higher risk for nosocomial infection, and it was important for hospitals to develop an admission screening process. First, temperature tests were performed at the entrances of the hospital, the outpatient clinic and the wards, and contacts and travel histories of all individuals in the epidemic area were recorded. Second, for patients preparing for hospital admission, compulsory routine blood tests, COVID-19 virus nucleic acid tests and IgM/G, high-resolution CT scans of the lungs were performed. Third, the confirmed cases were transferred to a designated hospital. Patients excluded from having COVID-19 received cancer treatment. Before admission, patients awaiting surgery were contacted by telephone and checked for symptoms related to covid-19 and referred for swabs $48 \mathrm{~h}$ before surgery (results available after $24 \mathrm{~h}$ ). In the case of a negative swab, the interview was repeated before surgery by medical personnel on the day of admission. Treatment was either postponed or cancelled only in cases of suspected covid-19 infection. In addition, at least 7 days prior to cancer treatment, cancer patients stayed in the observation ward and in isolation from 
other patients. To date, this strategy has permitted clinicians to adhere to surgical protocols for ovarian cancer $[43,48]$.

As to areas with relatively mild or low risk of epidemic, it was recommended to guarantee timely cancer therapy for tumor patients while preventing and controlling the epidemic. Medical institutions in non-epidemic areas in compliance with the requirements of prevention and control could appropriately open their gynecologic cancer clinics. With the gradual improvement of domestic epidemic situations, patients in non-epidemic areas followed up the original treatment plan, and were encouraged in the use of online treatment. When these patients were assessed for hospitalization, they were screened for reduction of nosocomial infection risk. For example, in case 3, the first symptom of covid-19 was in the digestive tract, and then followed by systems in the respiratory tract. Although there were no detectable abnormalities in lung CT examination, the new coronavirus nucleic acid RNA was detected and COVID-19 infection was diagnosed [46]. Therefore, it is necessary to be vigilant for patients with atypical coivd-19.

With the joint efforts of medical staff around the country, the epidemic has been well controlled in China. Recently, there is an increasing concern about asymptomatic COVID-19 carriers, particularly in one with ovarian cancer, as reported by Chen [10]. A 61-year-old female patient diagnosed as advanced ovarian cancer received a cytoreductive surgery plus intraperitoneal chemotherapy and subsequent first-line chemotherapy for 5 cycles. After the lockdown of Wuhan on January 23, 2020, the patient experienced a short therapy delay. On Feb 10, she complained of a slight dry cough without any other symptoms. Thereafter, she resumed hospitalization for the secondline chemotherapy owing to a poor control of CA-125. On March 21, screening of COVID-19 showed positive serum IgG antibodies to SARS-CoV-2, but negative on serum IgM antibodies, pulmonary CT and throat swab. It has been reported that, with the rapid spread of the disease, infections were diagnosed in individuals who had no direct contact with others with confirmed COVID-19 positive. Yang et al. demonstrated that only one of the three affected gynecological cancer patients was from the metropolitan Wuhan, and the others were from nearby [41]. In an epidemic area of COVID-19, more rigorous surveillance for SARS-CoV-2 should be performed before surgery. After surgery, if a patient develops symptoms of fever or is accompanied by cough, fatigue, sore throat, and/or diarrhea, etc., COVID-19 testing should then be implemented.

With the changing epidemic situation, hospitals in non-epidemic areas should pay special attention to the risk of imported covid-19 [12, 48]. For patients from high incidence areas, isolation observation was carried out in strict accordance with the requirements of the government departments. For suspected or confirmed cases of covid-19, we first treated covid-19 prior to starting cancer treatment. During the COVID-19 outbreak, many healthcare centres were confronted with high demand on pharmaceutical, equipment, and medical supplies, resulting in critical shortages. During this crisis, it was necessary to apply medical ethics in the clinical practice, aiming to treat and cure as many patients as possible with the best use of the available resources [34].

\section{Ovarian cancer management strategy was formulated according to pathological type, tumor stage and current treatment phase}

Although the treatment plan could be adjusted in the face of the epidemic, the therapeutic principles should remain unaltered. Ovarian cancer continues to be the leading cause of death in gynaecological malignancy worldwide. While covid-19 would have a significant impact on the diagnosis and treatment of ovarian cancer, the management strategies of these cancer patients were still determined by the tumor pathological type and the current treatment phase (Fig. 1). As in case 2 described by Zhang [46], surgery was the first line of treatment for ovarian cancer. However, blood supply and ICU (Intensive Care Unit) support could not be guaranteed during the epidemic period, necessitating neoadjuvant chemotherapy be first introduced to restrain tumor growth until the epidemic eases.

For presumed early stage ovarian cancers according to adnexectomy, restaging surgery could be deferred for 1 to 2 months if access to anesthesia-resuscitation was insufficient. Furthermore, in case of lack of anesthesiaresuscitation, a 2-step strategy was recommended for images suggestive of ovarian cancer on a solitary ovarian mass: adnexectomy of the suspect mass and decision to perform complete staging surgery on ultimate histologic analysis. In highly suspicious early-stage ovarian cancer, deferral surgery was not needed. It was recommended that the patient be referred to an oncologic COVID-19-free center after a complete evaluation that includes vaginal examination, MRI, transvaginal ultrasound, and serum markers (CA125). Intraoperative frozen section analysis was imperative to confirm the diagnosis. Surgical treatment of early-stage ovarian cancer was the standard of care by international guidelines [3, 11]. Young ( $<30$ years) asymptomatic patients with large $(\geq 10 \mathrm{~cm})$ benign adnexal masses must be submitted to surgery. Medical therapy is recommended in patients with apparently functional cysts unless it is contraindicated.

For advanced cancers which may require the use of postoperative recovery for cytoreduction surgery, neoadjuvant chemotherapy (NACT) should be the preferred choice even if primary cytoreduction surgery could be 


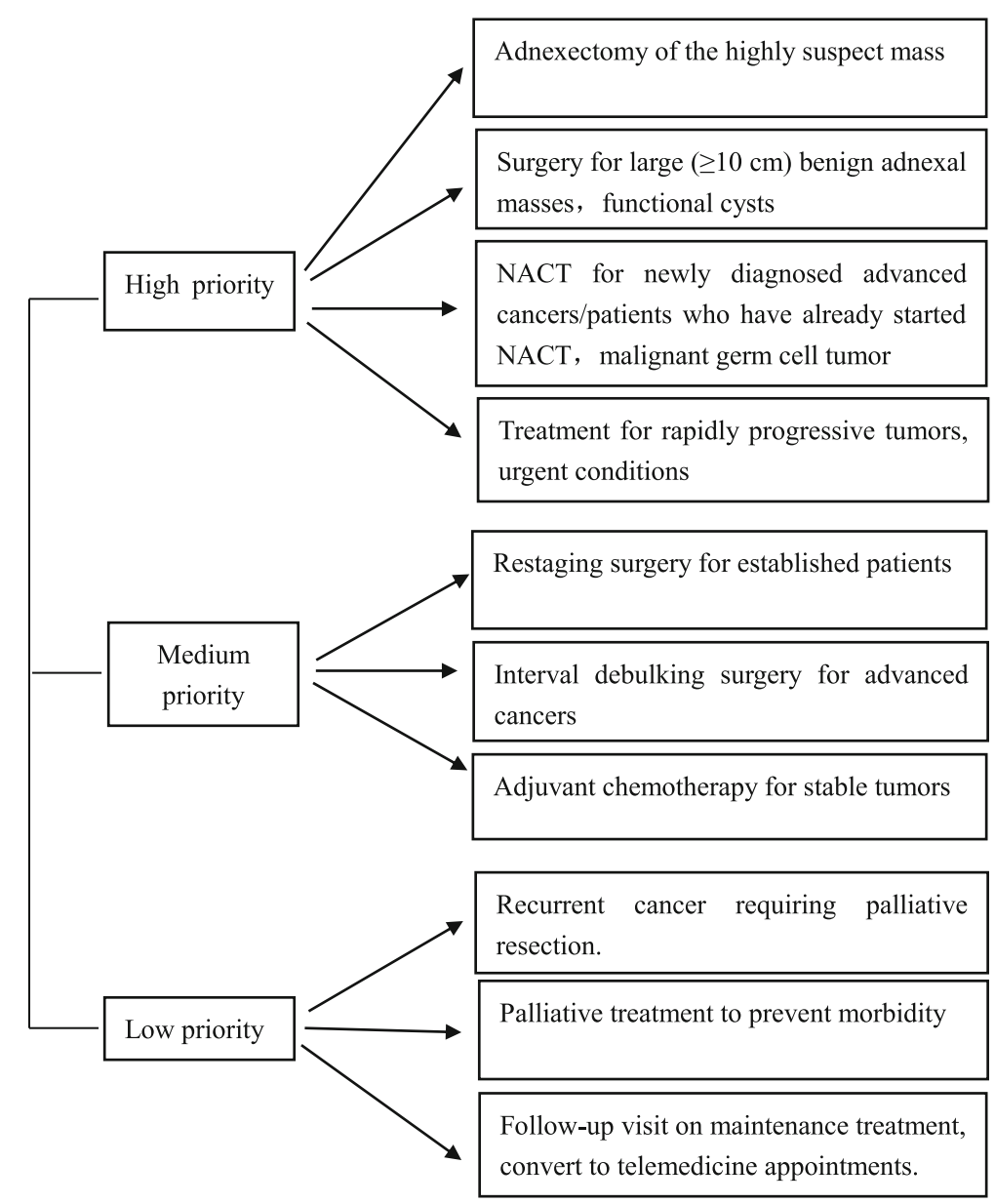

NACT: neoadjuvant chemotherapy

Fig. 1 Framework for prioritizing clinical management of ovarian cancer patients during COVID-19 pandemic

envisaged. If access to the operating room was restricted due to the crisis, patients scheduled to receive interval surgery after 3 or 4 cycles of chemotherapy could continue their chemotherapy and have surgery after 6 cycles of chemotherapy. The patient should then undergo at least two new cycles of chemotherapy after their closing surgery. Similar proposals were suggested by a multinational group of practitioners that put emphasis on NACT for advanced ovarian cancer even for tumors estimated to be resectable in order to decrease high risk surgeries and long ICU stays $[1,14,29]$. Another Chinese study identified the lack of strict guidelines for the management of gynecological cancer in an endemic region [38].

For chemotherapy-based patients, such as those with malignant germ cell tumor, one should give priority to the needs of these patients for chemotherapy; otherwise the tumor would progress more rapidly [43]. Physicians should determine whether chemotherapy could be temporarily delayed or changed, such as changing weekly treatment to a three-week duration and suspending radiotherapy sensitization chemotherapy to reduce the number of hospital visits. We also suggested that patients from other locations be treated in local hospitals, so as to divert patients and to reduce the aggregation of personnel in large hospitals.

With regard to newly diagnosed patients, tumor progression is more likely to be life-threatening. With the premise of guaranteeing the requirements of epidemic prevention and control, appropriate priority was given to ovarian tumor patients with relatively rapid tumor progression, and attention was paid to avoid tumor rupture, bleeding and other emergencies. Active cancer treatment during the epidemic period can prevent the rapid progress and fatality of the tumor. Although covid-19 infection might have occurred, it also gained time for the following cancer treatment. For example, it was completed as in case 3 reported by Yang [41]. However, patients in consolidation chemotherapy stage, or patients with tumor recurrence, whose short-term threat to life was relatively 
small or delayed treatment had little impact on prognosis, one could postpone treatment until conditions permit.

If the chemotherapy or surgery had to be performed after evaluation, the patients were admitted to the hospital for treatment as soon as possible under the condition of adequate protection. Some cancer patients could also have acquired COVID-19 infection on receiving cancer treatment during hospitalization. However, delaying cancer therapy could not be recommended as a reasonable choice to reduce the infection risk in the ongoing pandemic. Stronger personal protection, including protection for their families, were made for cancer patients [22].

\section{Specific considerations and the worldwide imposed treatment modifications for ovarian cancer during COVID- 19 era}

To date, the world has been fighting against COVID-19 since December 2019. The oncology community is being challenged, requiring a timely response to a fastchanging situation. Noteworthy modifications such as postponing elective operations, increasing rates of NACT in advanced illness, reducing/suspending surgery at recurrence and transforming to online consultation were recommended. The general guiding principle of these recommendations is the adoption of a "do no harm" method [1, 3, 11]. Nogami Y et al. demonstrated their experience in Tokyo. The surgery of an asymptomatic RT-PCR-positive patient was delayed by 4 weeks until the confirmation of negative results. The other two patients were RT-PCR-negative, but abnormal CT findings indicated the possibility of COVID-19, which delayed treatment. The patient who received NACT for ovarian cancer had clinically apparent deterioration because of the treatment delay [28]. Kobayashi $\mathrm{Y}$ et al. present two ovarian cancer cases whose treatment plan were affected by the local circumstances of COVID-19 in Daegu [19].

Frey MK and her colleagues revealed that types of surgery performed were different $(p=0.034)$, with fewer cytoreductive surgeries for ovarian cancer and laparoscopic procedures $(p=0.002)$ in 2020 [14]. Altın D et al. reported that most Turkish gynecologic oncologists modified their treatment of gynecologic cancers due to the COVID-19 pandemic. In Turkey,67.1\% of surgeons operated early stage ovarian cancer patients, $50 \%$ implemented NACT to all advanced stage ovarian cancers and $50 \%$ administered more cycles of NACT prior to interval debulking surgery [2].

It has been proposed that gynecologic cancer surgery should continue during the COVID-19 pandemic while complying with the established infection control measures. Postponement or non-surgical management should only be considered in patients with identified infection $[4$,
13]. Leung et al. held that maintaining surgical volume with detailed planning by a cohesive multidisciplinary team is practicable during the COVID-19 pandemic but this was associated with an increase in postoperative complications owing to a number of reasons [21].

The European Network of Gynaecological Cancer Advocacy Groups (ENGAGe) conducted a survey in 16 European countries and found that gynaecological cancer patients expressed significant anxiety about progression of their disease due to modifications of care related to the COVID-19 pandemic and wished to pursue their treatment as planned despite the associated risks [16].

\section{Conclusions}

The current COVID-19 pandemic has imposed excessive burdens to the healthcare system. Priority should always be given to the life-threatening circumstance. Treatment cancellation and delaying surgeries are challenging decisions. When confronted with limited resources during the COVID-19 pandemic, a multidisciplinary cancer treatment team (which may include medical ethicists and palliative care specialists) must decide which patients will receive complicated or critical care based on the expected clinical outcomes [27]. Relatively younger age, presumed immunecompromised and delay in cancer remedy were associated with significantly higher levels of cancer worry, anxiety and depression. Healthcare experts should consider or incorporate patients perspectives when making decisions that impact patients care during the pandemic crisis.

Furthermore, ensuring the continuum of care for ovarian cancer patients is crucial and is considered a major priority during the epidemic. Therapeutic regime of ovarian cancers should be based on patients individual characteristics, taking into consideration local COVID19 infection situation and accessibility of medical facilities. Prognosis is also a crucial consideration if delay is contemplated. Medical institutions are recommended to make full use of the internet medical service platform to establish rapid online consultation, health assessment, and education. Experts could also be organized to carry out online health consultation, disease prevention and control lectures, so that the patients are aware of their own health status and receive reasonable and orderly treatment under professional guidance. However, in case of cancer progression or worsening of the disease, patients should visit an oncologist rather than seeking cure through online consultation. Evidence in regard to these recommendations is limited because of the novel and unknown nature of the COVID-19 pandemic. Furthermore, data in relation to ethical debates about delayed therapy and therapy deviating from current guidelines are also in shortage. There is an urgent need for welldesigned trials to identify the clinical outcomes of continuing or withholding cancer therapy and the proper 
prevention, management, and treatment of COVID-19 in the oncology settings.

So far, China has continued to implement actions to control any resurgence of new cases of COVID-19. Despite the challenges encountered during the COVID-19 pandemic, we believe that appropriate shielding and screening protocol in place for our patients accompanied by a sturdy mitigation plan to protect surgical and medical faculty would ensure the delivery of safe ovarian cancer treatment service.

\section{Acknowledgements}

The authors thank Kecheng Huang for providing literature search assistance in the development of this manuscript.

\section{Authors' contributions}

Zhilan Chen and Chun Zhang drafted the manuscript. Benjamin K. Tsang designed the topic and revised the manuscript. Yinjiu, Xin Xin, Hemei Li and Yapei Wang collected the data. Qinghua Zhang revised the manuscript. All authors read and approved the final manuscript and agree to be accountable for all aspects of the work.

\section{Funding}

Not applicable.

\section{Availability of data and materials}

Not applicable.

\section{Ethics approval and consent to participate}

Not applicable.

\section{Consent for publication}

All named authors take responsibility for the integrity of the work as a whole, and have given their approval for this version to be published.

\section{Competing interests}

The authors declare that they have no competing interests.

\section{Author details}

'Department of Obstetrics and Gynecology, The Central Hospital of Wuhan, Tongji Medical College, Huazhong University of Science and Technology, No. 26 Shengli Street, Jiangan District, Wuhan 430014, China. ${ }^{2}$ Department of Obstetrics and Gynecology and Cellular and Molecular Medicine, University of Ottawa, and Chronic Disease Program, Ottawa Hospital Research Institute, Ottawa, Ontario, Canada.

Received: 18 October 2020 Accepted: 8 February 2021 Published online: 18 February 2021

\section{References}

1. Akladios C, Azais H, Ballester M, Bendifallah S, Bolze PA, Bourdel N, et al. Recommendations for the surgical management of gynecological cancers during the COVID-19 pandemic - FRANCOGYN group for the CNGOF. J Gynecol Obstet. 2020:49(6):101729.

2. Altın D, Yalçın I, Khatib G, Dağgez Keleşoğlu M, Akgöl S, Önder AB, et al. Management of gynecological cancers in the COVID-19 era: a survey from Turkey. J Turk Ger Gynecol Assoc. 2020;21(4):265-71.

3. Armstrong DK, Alvarez RD, Bakkum-Gamez JN, Barroilhet L, Behbakht K, Berchuck A, et al. NCCN Guidelines Insights: Ovarian Cancer, Version 1.2019. J Natl Compr Cancer Netw. 2019;17(8):896-909.

4. Ayhan A, Oz M, Topfedaisi Ozkan N, Aslan K, Altintas Ml, Akilli H, et al. Perioperative SARS-CoV-2 infection among women undergoing major gynecologic cancer surgery in the COVID-19 era: A nationwide, cohort study from Turkey. Gynecol Oncol. 2020;S0090-8258(20):34125-1.

5. Basse C, Diakite S, Servois V, Frelaut M, Noret A, Bellesoeur A, et al. Characteristics and outcome of SARS-CoV-2 infection in cancer patients. medRxiv. https://doi.org/10.1101/2020.05.14.20101576.
6. Benelli G, Buscarini E, Canetta C, Piana GL, Merli G, Scartabellati A, et al. SARS-COV-2 comorbidity network and outcome in hospitalized patients in Crema, Italy. medRxiv. https://doi.org/10.1101/2020.04.14.20053090.

7. Chen NS, Zhou M, Dong X, Qu JM, Gong FY, Han Y, et al. Epidemiological and clinical characteristics of 99 cases of 2019 novel coronavirus pneumonia in Wuhan, China:a descriptive study. Lancet. 2020;6736(20):30211-7.

8. Chen T, Wu D, Chen HL, Yan WM, Yang DL, Chen G, et al. Clinical characteristics of 113 deceased patients with coronavirus disease 2019: retrospective study. BMJ. 2020;368:m1091.

9. Chen TL, Dai Z, Mo PZ, Li XY, Ma ZY, Song SH, et al. Clinical characteristics and outcomes of older patients with coronavirus disease 2019 (COVID-19) in Wuhan, China (2019): a single-centered, retrospective study. J Gerontol A Biol Sci Med Sci. 2020;75(9):1788-95.

10. Chen YS, Li GL. Gynecological malignancies with asymptomatic SARS-CoV-2 infection during the convalescence of outbreak. Gynecol Oncol. 2020;158(1):44-6.

11. Colombo N, Sessa C, du Bois A, Ledermann J, McCluggage WG, McNeish I, et al. ESMO-ESGO consensus conference recommendations on ovarian cancer: pathology and molecular biology, early and advanced stages, borderline tumours and recurrent disease. Ann Oncol. 2019;30(5):672-705.

12. Dai MY, Liu DB, Liu M, Zhou FX, Li GL, Chen Z, et al. Patients with cancer appear more vulnerable to SARS-CoV-2: a multicenter study during the COVID-19 outbreak. Cancer Discov. 2020;10(6):783-91.

13. Dursun $P$, Dervisoglu H, Daggez M, Turan T, Kiliç F, Tekin ÖM, et al. Performing gynecologic cancer surgery during the COVID-19 pandemic in Turkey: a multicenter retrospective observational study. Int J Gynaecol Obstet. 2020;151(1):33-8.

14. Frey MK, Ellis AE, Zeligs K, Chapman-Davis E, Thomas C, Christos PJ, et al. Impact of the coronavirus disease 2019 pandemic on the quality of life for women with ovarian cancer. Am J Obstet Gynecol. 2020;223(5):725.e1-9.

15. Guan WJ, Liang WH, Zhao Y, Liang HR, Chen ZS, Li YM, et al. Comorbidity and its impact on 1590 patients with Covid-19 in China: a Nationwide analysis. Eur Respir J. 2020;55(5):2000547.

16. Gultekin M, Ak S, Ayhan A, Strojna A, Pletnev A, Fagotti A, et al. Perspectives, fears and expectations of patients with gynaecological cancers during the COVID-19 pandemic: A Pan-European study of the European Network of Gynaecological Cancer Advocacy Groups (ENGAGe). Cancer Med. 2020;18. https://doi.org/10.1002/cam4.3605.

17. Joharatnam Hogan N, Hochhauser D, Shiu KK, Rush H, Crolley V, Butcher E, Sharma A, et al. Outcomes of the 2019 Novel Coronavirus in patients with or without a history of cancer - a multicentre North London experience. medRxiv. https://doi.org/10.1101/2020.04.16.20061127.

18. Kuderer NM, Choueiri TK, Shah DP, Shyr Y, Rubinstein SM, Rivera DR, et al. Clinical impact of COVID-19 on patients with cancer (CCC19): a cohort study. Lancet. 2020;395(10241):1907-18.

19. Kobayashi Y, Suh DH, Aoki D, Kim JW. Management of ovarian cancer patients in affected areas during COVID-19 pandemic: Japan and Korea. J Gynecol Oncol. 2020;31(3):e65.

20. Lee LY, Cazier JB, Angelis V, Arnold R, Bisht V, Campton NA, et al. COVID-19 mortality in patients with cancer on chemotherapy or other anticancer treatments: a prospective cohort study. Lancet. 2020;395(10241):1919-26.

21. Leung E, Pervaiz Z, Lowe-Zinola J, Cree S, Kwong A, Marriott N, et al. Maintaining surgical care delivery during the COVID-19 pandemic: A comparative cohort study at a tertiary gynecological cancer centre. Gynecol Oncol. 2020;50090-8258(20):34216-5.

22. Liang WH, Guan WJ, Chen RC, Wang W, Li JF, Xu K, et al. Cancer patients in SARSCoV-2 infection: a nationwide analysis in China. Lancet Oncol. 2020;21(3):335-7.

23. Mehta V, Goel S, Kabarriti R, Cole D, Goldfinger M, Acuna-Villaorduna A, et al. Case fatality rate of cancer patients with COVID-19 in a New York hospital system. Cancer Discov. 2020;10(7):935-41.

24. Meng YF, Lu WR, Guo ES, Liu J, Yang B, Wu P, et al. Cancer history is an independent risk factor for mortality in hospitalized COVID-19 analysis. $J$ Hematol Oncol. 2020;13(1):75.

25. Miyashita H, Mikami T, Chopra N, Yamada T, Chernyavsky S, Rizk D, Cruz C, et al. Do patients with cancer have a poorer prognosis of COVID-19? An experience in New York City. Ann Oncol. 2020;31(8):1088-9.

26. Nakayama J, El-Nashar SA, Waggoner S, Traughber B, Kesterson J. Adjusting to the new reality: evaluation of early practice pattern adaptations to the COVID-19 pandemic. Gynecol Oncol. 2020;158(2):256-61.

27. Nikpouraghdam M, Farahani AJ, Alishiri GH, Heydari S, Ebrahimnia M, Samadinia $\mathrm{H}$, et al. Epidemiological characteristics of coronavirus disease 2019 (COVID-19). J Clin Virol. 2020;127:104378. 
28. Nogami Y, Kobayashi Y, Tsuji K, Yokota M, Nishio H, Nakamura M, et al. Impact of the COVID-19 epidemic at a high-volume facility in gynecological oncology in Tokyo, Japan: a single-center experience. J Ovarian Res. 2020;13(1):105.

29. Ramirez PT, Chiva L, Eriksson AGZ, Frumovitz M, Fagotti A, Gonzalez Martin A, et al. COVID-19 global pandemic: options for management of gynecologic cancers. Int J Gynecol Cancer. 2020;30(5):561-3.

30. Robilotti EV, Babady NE, Mead PA, Rolling T, Perez-Johnston R, Bernardes M, et al. Determinants of severity in cancer patients with COVID-19 illness. medRxiv. https://doi.org/10.1101/2020.05.04.20086322.

31. Rossi $P G$, Marino M, Formisano D, Venturelli $F$, Vicentini M, Grilli $R$, et al. Characteristics and outcomes of a cohort of SARS-CoV-2 patients in the province of Reggio Emilia, Italy. Plos One. 2020;15(8):e0238281.

32. Russell B, Moss C, Papa S, Irshad S, Ross P, Spicer J, et al. Factors affecting COVID-19 outcomes in cancer patients: A first report from Guy's Cancer Centre in London. medRxiv. https://doi.org/10.1101/2020.05.12.20094219.

33. Trapani D, Marra A, Curigliano G. The experience on coronavirus disease 2019 and cancer from an oncology hub institution in Milan, Lombardy Region. Eur J Cancer. 2020;132:199-206.

34. Ueda M, Martins R, Hendrie PC, McDonnell T, Crews JR, Wong TL, et al. Managing cancer care during the COVID-19 pandemic: agility and collaboration toward a common goal. J Natl Compr Cancer Netw. 2020;20:1-4.

35. Wang H, Zhang L. Risk of COVID-19 for patients with cancer. Lancet Oncol. 2020;21(4):e181.

36. Wang J, Song QB, Chen Y, Wang ZJ, Chu Q, Gong HY, et al. Systematic investigations of COVID-19 in 283 cancer patients. medRxiv. https://doi. org/10.1101/2020.04.28.20083246.

37. Wang L, He WB, Yu XM, Hu DL, Bao MW, Liu HF, et al. Coronavirus disease 2019 in elderly patients: characteristics and prognostic factors based on 4week follow-up. J Inf Secur. 2020;80(6):639-45.

38. Wang YM, Zhang SQ, Wei LH, Lin ZQ, Wang XY, Wang JL, et al. Recommendations on management of gynecological malignancies during the COVID-19 pandemic: perspectives from Chinese gynecological oncologists. J Gynecol Oncol. 2020;31(4):e68.

39. World Health Organization, Available from: https://www.who.int/docs/defa ultsource/coronaviruse/who-china-joint-mission-on-covid-19-final-report-11 00hr-28feb2020-11 mar-update.pdf. Accessed 22 Mar 2020

40. Yang $\mathrm{KY}$, Sheng $\mathrm{YH}$, Huang $\mathrm{CL}$, Jin $\mathrm{Y}$, Xiong $\mathrm{N}$, Jiang $\mathrm{K}$, et al. Clinical characteristics, outcomes, and risk factors for mortality in patients with cancer and COVID-19 in Hubei, China: a multicentre, retrospective, cohort study. Lancet Oncol. 2020;21(7):904-13.

41. Yang SH, Zhang Y, Cai J, Wang Z-H. Clinical Characteristics of COVID-19 After Gynecologic Oncology Surgery in Three Women: A Retrospective Review of Medical Records. Oncol. 2020;25:1-4.

42. Yarza R, Bover M, Paredes D, López-López F, Jara-Casas D, Castelo-Loureiro $A$, et al. SARS-CoV-2 infection in cancer patients undergoing active treatment: analysis of clinical features and predictive factors for severe respiratory failure and death. Eur J Cancer. 2020;135:42-250.

43. Yu J, Ouyang W, Chua MLK, Xie C. SARS-CoV-2 transmission in patients with cancer at a tertiary care hospital in Wuhan, China. JAMA Oncol. 2020;6(7): 1108-10.

44. Zhang HY, Wang LW, Chen YY, Shen XK, Wang Q, Yan YQ, et al. A Multicenter study of coronavirus disease 2019 outcomes of cancer patients in Wuhan, China. medRxiv. https://doi.org/10.1101/2020.03.21.20037127.

45. Zhang HY, Wang LW, Chen YY, Wu QJ, Chen GL, Shen XK, et al. Outcomes of novel coronavirus disease 2019 (COVID-19) infection in 107 patients with cancer from Wuhan, China. Cancer. 2020;126(17):4023-31.

46. Zhang J, Peng P, Li X, Zha YF, Xiang Y, Zhang GN, et al. Management strategies for three patients with gynecological malignancies during the outbreak of COVID-19. Zhonghua Fu Chan Ke Za Zhi. 2020:55(4):221-6.

47. Zhang JX, Wang XL, Jia XM, Li J, Hu K, Chen GZ, et al. Risk factors for disease severity, unimprovement, and mortality of COVID-19 patients in Wuhan, China. Clin Microbiol Infec. 2020;26:767-72.

48. Zhang L, Zhu F, Xie L, Wang C, Wang J, Chen R. Clinical characteristics of COVID-19-infected cancer patients: a retrospective case study in three hospitals within Wuhan, China. Ann Oncol. 2020;31 (7):894-901.

\section{Publisher's Note}

Springer Nature remains neutral with regard to jurisdictional claims in published maps and institutional affiliations.

Ready to submit your research? Choose BMC and benefit from:

- fast, convenient online submission

- thorough peer review by experienced researchers in your field

- rapid publication on acceptance

- support for research data, including large and complex data types

- gold Open Access which fosters wider collaboration and increased citations

- maximum visibility for your research: over $100 \mathrm{M}$ website views per year

At BMC, research is always in progress.

Learn more biomedcentral.com/submissions 